\title{
Cambio Climático: las contradicciones del capitalismo contemporáneo en la producción de maíz en México
}

\author{
Manuel Antonio Espinosa Sánchez \\ Universidad Nacional Agraria; Managua, Nicaragua. \\ Email: manuelantonioespinosa@gmail.com
}

\begin{abstract}
Resumen: Este ensayo retoma algunos planteamientos de la agroecología y pretende clarificar las relaciones entre el cambio climático y el capitalismo, a propósito del sistema agrícola centrado en la producción de maíz en México. A su vez, pretende dilucidar las implicaciones de la agricultura sustentable que plantea el IPCC y los imperativos de ruptura y contradicción propios de la reproducción del capital y el conflicto que subyace entre agricultura campesina y agricultura industrial.
\end{abstract}

Palabras clave: agroecología, neomarxismo, agricultura campesina

\section{Climate Change: the contradictions of contemporary capitalism in the production of maize in Mexico}

Abstract: This essay returns to some of the approaches of agroecology and aims to clarify the relationship between climate change and capitalism, referring to the agricultural system focused on maize production in Mexico. In turn, it seeks to clarify the implications of sustainable agriculture posed by the IPCC and the imperatives of fracture and contradiction intrinsic to the reproduction of capital and the conflict that underlies between peasant farming and industrial agriculture.

Keywords: agroecology, neomarxism, peasant farming

\section{Mudanças climáticas: as contradições do capitalismo contemporâneo na produção de milho no México}

Resumo: Este ensaio recoloca algumas abordagens da agroecologia e visa clarificar as relações entre as mudanças climáticas e o capitalismo, a partir do sistema agrícola voltado para a produção de milho no México. Por sua vez, procura esclarecer as implicações de uma agricultura sustentável colocado pelo IPCC e os imperativos de ruptura e contradição próprios da reprodução do capital e subjacente conflito entre a agricultura camponesa e a agricultura industrial.

Palavras-chave: agroecologia, neo-marxismo, agricultura camponesa 


\section{Introducción}

Esta reflexión se origina porque al revisar la vasta literatura sobre el cambio climático se encuentran diversos análisis y recomendaciones muy minuciosos que relacionan la emisión de gases con efecto invernadero como el CO2 con el incremento de la temperatura en la biósfera del planeta pero que, al plantearse las posibles alternativas, estas parecieran redundar en estrategias que sugieren la perpetuación del modelo industrial que ha originado el problema ecológico en cuestión (IPCC, 2012).

Si la variabilidad climatológica afectará fuertemente al sistema agrícola en México (IPCC, 2007), nos preguntamos por los nexos entre el modelo económico dominante, el capitalismo, y el aparato agroindustrial en la producción de maíz para tratar de interpretar en nuestro contexto histórico específico las implicaciones de adaptación y mitigación ante sequías, lluvias excesivas, etcétera.

En tanto las alternativas que se plantean sobre el cambio climático hacen referencia a sistemas agrícolas sustentables, buscamos aquí clarificar cómo sería eso en el contexto mexicano y cuáles son las implicaciones para la agricultura industrial de alta productividad.

Encontramos que la agricultura campesina como la describen Altieri y Toledo (2011) es una alternativa posible frente al cambio climático. No obstante, la agricultura industrial capitalista entraña una lógica de apropiación individual de bienes comunes (como los servicios ecológicos y las semillas) y de riqueza social (trabajo, intercambios y conocimiento colectivo) que es el origen contradictorio que entraña la acumulación del capital y por ende es incompatible con una agricultura sustentable, que en México sería la agricultura campesina (Bartra, 2008).

Por lo anterior, nos situamos críticos de aquellos planteamientos sistemáticos en la literatura que implícitamente hacen creer que es posible mitigar el cambio climático dentro de la agricultura industrial capitalista.

En definitiva, consideramos que el viraje hacia una forma distinta de agricultura maicera tiene implicaciones que requieren una discusión de proyecto de nación y paradigma civilizatorio en ruptura con el capitalismo contemporáneo.

\section{El capitalismo contemporáneo como fenómeno mundial}

Desde finales del Siglo XX, existe un creciente consenso de que nos encontramos ante un cambio sistémico y social cuyo origen e impacto, con algunas variaciones según el enfoque disciplinar y la postura política del autor en cuestión, se relaciona con el capitalismo y con el paradigma de la modernidad (Harvey, 1998). El debate de este fenómeno en la sociología se centra en la interpretación del capitalismo y el grado de correlaciones con 
las transformaciones verificadas en las dinámicas sociales que nos configuran, lo que genera un amplio disenso en nuestros países latinoamericanos (Escobar, 2010).

La literatura y sus discursos analíticos recurren al rescate y reformulación de una variedad de conceptualizaciones que pretenden dar cuenta de los nexos entre ámbitos y fenómenos societales que eventualmente se consideraron en distintas dimensiones, o sea, como aspectos del todo social cuyos espacios, tiempos y dinámicas se analizaban por separado pero que hoy se perciben integrados de forma cada vez más compleja: capitalismo tardío, capitalismo informacional, postcapitalismo, capitalismo posmoderno, postindustrialismo, son algunos términos que, directamente relacionados con la modernidad como paradigma civilizatorio, intentan dar cuenta de esta fase del capitalismo contemporáneo en el que nos encontramos.

Siguiendo a Bech, Giddens y Lash (1994) podemos distinguir dos grandes tendencias con relación al debate de la modernidad, una planteada por Lyotard (1989) en términos de encontrarnos en una nueva época civilizatoria marcada por una cultura que ha dado lugar al paradigma de la postmodernidad reflejado en dinámicas socioculturales fragmentarias, discontinuas y profundamente decepcionada de los metarrelatos pero altamente vinculado a la industrialización y permisivo al capitalismo y su saber técnico; y otra tendencia es la planteada por los que consideran que los cambios civilizatorios están aparejados con el capitalismo en donde figuran la escuela funcionalista y la del capitalismo tardío quienes han intentado dar cuenta del fracaso del proyecto ilustrado de frente a graves inconsistencias, entre ellas el mar de empobrecidos en casi todo el orbe. ${ }^{1}$

Por su parte, Lash (1997), Luhmann (1997), Harvey (1998), Giddens (2000), y otros, sostienen que en realidad la posmodernidad es un discurso autoaclaratorio dentro de la modernidad que, a partir de las innovaciones tecnológicas informacionales y comunicacionales y su concomitante posibilidad de incidencia virtual a escala mundial, ha logrado que el capitalismo se incorpore en diversos ámbitos de la cultura y de la subjetividad que ha resultado en una complejización espacio-tiempo de fenómenos sociales antes no tan claramente asociados. Según Fair (2008), habría que rechazar el concepto de posmodernidad como ruptura con la modernidad y acogerlo como un momento específico de la modernidad cuya fenomenología en el todo social se distingue en términos de un sistema global neoliberal. ${ }^{2}$

No obstante, lo que llamamos aquí capitalismo contemporáneo consiste en un fenómeno que ha consolidado las esferas de lo cultural (subjetividad) y de la economía (medios de producción) usando como dispositivo de síntesis las redes informacionales y medios de comunicación, con lo que el capital adquirió una nueva forma de reproducirse y de des-localizarse. La emergencia tecnológica de interacciones virtuales a través de la internet y de las redes satelitales de comunicación permitió que se verificara un descentramiento de las relaciones de producción industrial, antes únicamente localizadas de forma física en las fábricas, y una atomización de la identidad 
obrera lo que diluyó su antagonía política hacia la clase burguesa (Lash, 1997).

Por otro lado, Altamira (2006) señala cómo ese nuevo sujeto obrero o trabajador inmaterial tiene su correlato en el nuevo sujeto consumidor en donde las mercancías constituyen la base material de la identidad e intersubjetividad. Es una fase en la que priva el desdibujo de las fronteras entre producción-mercancía y fuentes de intersubjetividad en la construcción de la identidad social. Así, la producción material deja de estar concentrada en un mismo lugar y se traslada a diversas localidades que, con la flexibilidad laboral, los sistemas de ensamble automatizados y el outsourcing, desintegra la noción de obrero-individuo por la de múltiples procesos de manufactura que difieren en el espacio y el tiempo:

“En la era del obrero social la fábrica, con la ayuda de la tecnología informativa, se diseminará en la sociedad, desterritorializando, dispersando y descentralizando las operaciones, para constituir lo que el autonomismo llamó la fábrica difusa” (Altamira, 2006: 64).

Por el lado del consumo, las mercancías atienden a necesidades creadas por la vía del marketing que las promocionan como fuente de identidad y dispositivo de intersubjetividad, de sentimiento de propósito y teleología, es la emergencia de la economía cultural:

“Esta nueva burguesía “yuppificada” se caracteriza por adorar el consumo de mercancías innecesarias, "superficialidad fabricada" (Harvey, 1998: 108), que actúan como símbolos de status que otorgan “distinciones de envidia” con respecto a otros grupos de menores ingresos” (Fair, 2008: 4).

Las redes comunicacionales, entonces, han sido útiles para establecer flujos de información, datos y comunicación en tiempo real beneficiando la interconexión de los procesos de producción industrial, la coordinación de las dinámicas de inversión de capital y movilidad financiera, y la difusión de patrones de consumo de mercancías-identidades. ${ }^{3}$ Este fenómeno, en breve, ha permitido una transformación en la reproducción del capital y su amalgamiento a la esfera de la intersubjetividad al colocar manufacturas como símbolos de identidad.

Este capitalismo contemporáneo se encuentra íntimamente vinculado con la ideología neoliberal (Bech, Giddens y Lash, 1994). Esto es, reformas jurídicas e institucionales buscando una profunda reestructuración del Estado benefactor-populista que ahora, en una versión mínima y gerencial, habría de permitir la libre operación de los mercados. Esto implicó en la década de los noventas la privatización de empresas estatales, la desregulación de los mercados internos, la apertura de la economía al capital extranjero, una política monetaria de libre flotación, y la contracción del gasto público social, entre otras medidas:

“Esto permitiría a sus países “insertarse en el mundo”, obtener el creci- 
miento de sus economías y generar, mediante una “mano invisible”, el "derrame" que garantizara el "desarrollo sustentable" que se distribuiría espontáneamente a todos los habitantes del planeta” (Fair, 2008: 6).

Este capitalismo contemporáneo y su énfasis neoliberal, ha tenido su complemento en un individualismo político, esto es, el desmantelamiento de las redes sociales físicas -comunitarias, locales y cara a cara- que da paso a la racionalidad del esfuerzo propio y a la construcción de identidad política a través de los medios de comunicación e información, como la televisión, revistas, radio y recientemente la internet. El achicamiento del Estado-nacional benefactor de los ochentas, conllevó el desfondamiento de los sistemas colectivos de debate y participación política, en donde se tematizaban diversas problemáticas locales que podían ser planteadas a través de los mecanismos formales que instituyeron los gobiernos del populismo y los informales tradicionales en los barrios urbanos y pueblos rurales. En definitiva, la condición posmoderna de este capitalismo contemporáneo neoliberal, no sólo se ha consolidado en nuevas formas de producción de mercancías y de consumo de manufacturas como símbolos de identidad, sino también ha despolitizado lo político transitando hacia una moral de la libertad individual. Es el fin de la historia marcado por la imposibilidad de las utopías altermundistas, evidenciadas por la caída del muro de Berlín y el colapso de los países del bloque socialista:

“Esta despolitización, sin embargo, no sólo afectará a los trabajadores en general y a los sectores populares en particular, sino que incluirá también a gran parte de la sociedad, expresándose en un notorio declive a nivel planetario en el apoyo a los partidos, sindicatos y a la actividad política en general” (Fair, 2008: 7).

Por lo anterior, el capitalismo actual -como forma civilizatoria- hubo de recurrir, desde la mitad del Siglo XX, a un discurso neodarwineano sobre la naturalidad del individualismo económico, de la virtud de la propiedad privada y de las ventajas incomparables de la tecnología y el confort como destino natural del ser humano. Con el discurso de Harry Truman sobre el desarrollo (Escobar, 2010), el capitalismo habría de constituirse en la mejor y más avanzada forma civilizatoria posible. Sin embargo, no han sido las contradicciones propias del antagonismo entre la clase neo-obrera y la neo-burguesa, ni las contradicciones entre capital virtual y trabajo difuso, ni tampoco las contradicciones entre la acumulación de pocos y la depauperización de muchos, sino que ha sido una contradicción mucho más fundamental la que ha sentenciado la inviabilidad del capitalismo actual como forma civilizatoria: la Naturaleza a través del fenómeno del cambio climático.

\section{El Cambio Climático: fenomenología global y impactos locales}

El Panel Intergubernamental para el Cambio Climático ha publicado información y datos que permiten describir el fenómeno del cambio climático de la siguiente manera: 
"Hay evidencia observada en todos los continentes y la mayoría de los océanos muestran que muchos sistemas naturales están siendo afectados por cambios climáticos regionales, particularmente en aumentos de temperatura. Una evaluación global de los datos desde el año 1970 ha mostrado que es probable que el calentamiento antropogénico haya tenido una influencia discernible sobre muchos sistemas físicos y biológicos. Están surgiendo otros efectos de los cambios climáticos regionales sobre entornos naturales y humanos, aunque muchos son difíciles de discernir debido a los factores de adaptación y no climáticos” (IPCC, 2007: 8-9).

Otras instituciones como The Royal Society (2012) y el World Resources Institute (2009) han presentado datos, informes y proyecciones en el sentido de encontrarnos en una encrucijada ante un desastre ecológico de proporciones planetarias irreversibles causadas por efectos antropogénicos y verificables a través de la medición de la temperatura en la superficie del planeta, el nivel medio del mar y la cubierta de nieve (Figura 1). Estos efectos antropogénicos, según el reporte del (IPCC Working Group II, 2007), están originados principalmente por el incremento en las emisión de gases con efecto invernadero, la desaparición de amplias áreas boscosas y la insuficiente tasa de absorción de carbono y de otros contaminantes por parte de biomas terrestres y costeros agotados.

\section{Figura 1. Media en la temperatura superficial, el nivel medio del mar y la cubierta de nieve en el hemisferio Norte de 1850 a 2001.}

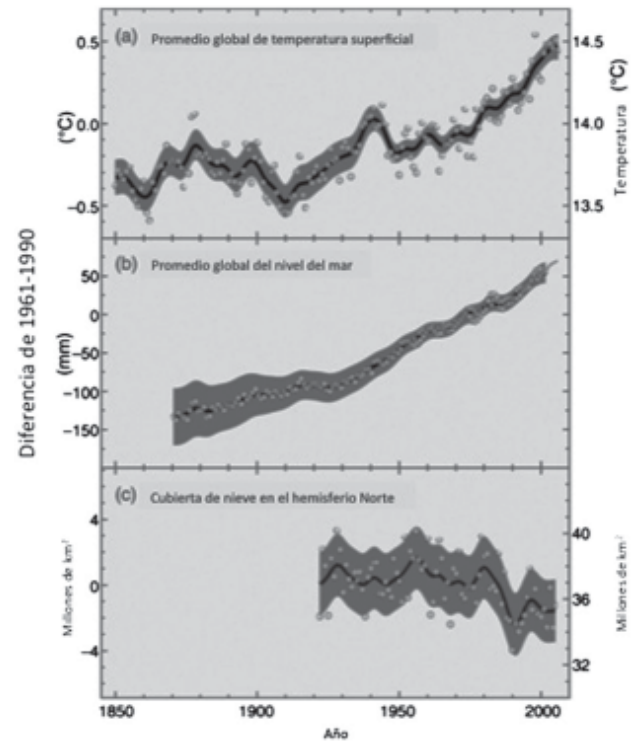

Fuente: (IPCC, 2007: 9). 
El calentamiento global, en definitiva, corresponde al incremento de la temperatura y a la variabilidad de las lluvias, a su vez esto representa un aumento en los fenómenos meteorológicos extremos (huracanes, granizo, heladas, sequías). Según el último informe del IPCC (2012), las sequías se intensificarán durante este siglo en algunas zonas de Europa Central, América Central, México, el Noreste de Brasil y el Sur de África.

Siguiendo a Martínez-Alier (2011) consideramos que el cambio climático no sólo constituye una amenaza para diversas especies de flora y fauna, incluidos los seres humanos, sino que actualmente exhibe efectos devastadores para aquellas sociedades rurales cuya subsistencia depende directamente de los servicios ecológicos que proporcionan bosques, selvas y ecosistemas marinos, sean por actividades agrícolas, pastoriles, de recolección y/o pesca:

"Muchos conflictos ecológicos, tengan lugar dentro o fuera del mercado, sean locales o globales, ocurren porque el crecimiento económico implica un incremento en el uso del medio ambiente. Esos impactos se notarían aunque no hubiera crecimiento económico, pues el actual nivel de actividad económica ya agota muchos recursos y sumideros” (Martínez-Alier, 2011: 16).

En el mismo orden de ideas, los enfoques de la economía ecológica ${ }^{4}$ y de la ecología política ${ }^{5}$ coinciden en señalar que la actual fase del capitalismo y su lógica de crecimiento económico han trastornado los sistemas bióticos y abióticos planetarios, en donde existen perdedores y ganadores:

“(...) el desarrollo capitalista ha generado conflictos ecológicos distributivos, sobretodo en el sur global, con los beneficios económicos concentrados en las manos de los relativamente ricos; mientras que los costos se pagan de manera desproporcionada por los pobres (indígenas, campesinos, trabajadores populares y pobladores de barrios marginados), en particular los que viven cerca de los focos de contaminación y aquellos cuyos medios de vida son amenazados” (Tetreault, Ochoa y Hernández, 2013: 18).

Entonces, diversos autores sugieren que existe una relación directa entre el cambio climático, o sea, el incremento en la temperatura media en la superficie del planeta y la fase actual del capitalismo en términos de encontrarnos con emisiones de gases de efecto invernadero insostenibles que se originan a partir del uso de combustibles fósiles para los procesos de producción industrial y generación de energía eléctrica, entre otras actividades, como la agricultura moderna (Figura 2). 
Figura 2. Proporción de emisiones de gases de efecto invernadero.

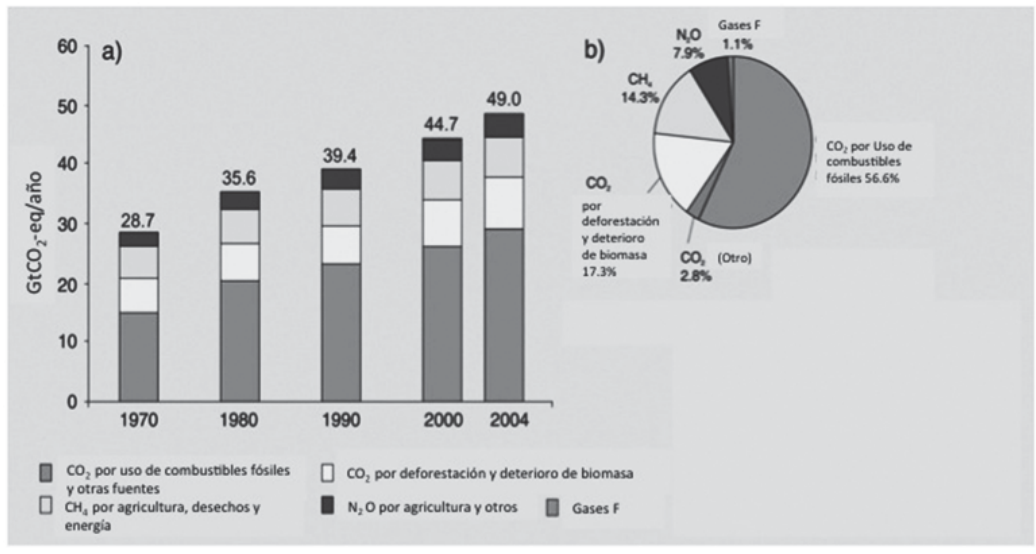

Fuente: (IPCC, 2007: 36).

No obstante, esta relación entre los procesos de crecimiento económico centrados en la producción industrializada de bienes de consumo y servicios que consumen energía originada en la quema de combustibles fósiles, fue ampliamente advertida desde la década de los ochentas y enunciada formalmente en el informe llamado Nuestro futuro común, por lo que lejos de estar experimentándose una desmaterialización en el capitalismo contemporáneo, más bien asistimos a un crecimiento en la lógica de extractiva de materiales, agua y fuentes de energía fosilizada que son la base física a partir de la cual se verifican los procesos de producción industrial en los que se reproduce el capital (Georgescu-Roegen, 1993).

Así, un primer nexo fundamental entre el capitalismo actual y el cambio climático consiste en que el proceso de producción de mercancías se ha incrementado y requiere de más energía de origen fósil, lo que a la postre resulta en mayores emisiones de gases de carbono y en el efecto de invernadero que ha calentado el planeta (World Resources Institute, 2009).

Un segundo nexo fundamental entre la forma actual de reproducción del capital y el cambio climático lo habremos de encontrar en las formas específicas de producción de bienes de consumo y mercancías, particularmente en la producción de alimentos. Esto es, el caso de la producción de maíz en México es un magnífico ejemplo de cómo el capitalismo actual ha extendido su influencia hacia la especialización y simplificación de los sistemas agrícolas maiceros pero que, nuevamente ante el cambio climático, la Naturaleza ha puesto en jaque al proceso industrializador agropecuario y, con ello, a su tendencia mercantilizadora de subjetividades que no ha logrado subsumir la identidad campesina (Bartra, 2011). En el mismo trance, las agencias internacionales (IPCC, 2012), las ONG's (The Royal Society, 2012) 
y algunos funcionarios gubernamentales mexicanos (Sarukhán, Carabias, Koleff y Urquiza-Haas, 2013) han señalado que es la agricultura multifuncional y diversificada la que podrá reducir las emisiones de gases que están calentando el planeta, y no la agricultura industrial capitalista.

\section{La agroindustrialidad y la agricultura campesina: el caso del maíz en México}

Desde mediados del Siglo XX en México, se implementó una intensa campaña para lograr incrementos en la productividad del maíz mediante la transformación del campesinado y su agricultura de autoconsumo para dar paso a una agricultura industrializada y la emergencia de un productor agropecuario moderno de tipo empresarial:

"La Revolución Verde surge sustentada en la idea errónea del hambre en el mundo y su solución con base en los insumos químicos en la agricultura, así como en las recientes leyes de Mendel sobre genética. En México, la Revolución Verde se presentó como una vía para la modernización del país y en específico del espacio rural que era visto como un espacio desprovisto de los medios necesarios para desarrollarse respecto a lo urbano" (Pichardo, 2006: 66).

Como parte de las influencias mundiales propias del capitalismo contemporáneo hacia el sistema agroalimentario maicero en México, a partir de la década de los noventa vinieron ocurriendo diversas transformaciones estructurales -cuyo culmen fue la firma del Tratado de Libre Mercado de América del Norte (TLCAN)- que fueron empujando la emergencia de un nuevo actor rural que habría de insertarse en la lógica del libre mercado; trastocándose así, las tradicionales estructuras agrarias corporativas y los sistemas campesinos de producción agrícola.

Siguiendo a (Nadal y Wise, 2009), coincidimos en que los efectos del TLCAN han sido devastadores para el campesinado mexicano que, con enorme asimetría e inequidad con respecto a sus contrapartes canadienses y norteamericanos, padecieron la reducción de subsidios y la desaparición de esquemas de precios de garantía, han asumido altos costos financieros y enormes riesgos de mercado y climatológicos, y han visto cómo se reducen sus márgenes de utilidad ante los incrementos en los precios de los insumos y el férreo control de precios. No obstante, algunos agricultores maiceros mexicanos han sido capaces de insertarse en la lógica del libre mercado con éxito variopinto (Hellin, Groenevald y Keleman, 2012).

A pesar de ello, acorde a Toledo, Alarcón-Chaires y Barón (2002), actualmente en México es posible encontrar múltiples arreglos de agroecosistemas centrados en la producción de maíz (Zea mays) (Tabla 1) en cuyos extremos se encuentran, por un lado, la producción agroindustrial del corporativo bajo el paradigma capitalista del agronegocio (Delgado 
Cabeza, 2010) y, en el otro, la producción seminómada para el autoconsumo de la comunidad que se complementa fuertemente con actividades de recolección silvestre (Haenn y Wilk, 2006).

\section{Tabla 1. Tendencias en la apropiación y manejo de los agroecosistemas.}

\begin{tabular}{l|l} 
Paradigma & Descripción del agroecosistema \\
\hline Silvestre & $\begin{array}{l}\text { Recolección de plantas silvestres como alimento y crianza de animales, se } \\
\text { desplaza conforme periodos estacionales y la disponibilidad de agua, pastos, } \\
\text { frutos, leña, etc. }\end{array}$ \\
\hline $\begin{array}{l}\text { Campesino- } \\
\text { multifuncional }\end{array}$ & $\begin{array}{l}\text { Cultivos criollos multifuncionales, crianza de especies menores, uso de materiales } \\
\text { locales como fuente principal de sustento, junto con la recolección de hierbas, } \\
\text { tubérculos y hongos; así como la caza y pesca. }\end{array}$ \\
\hline $\begin{array}{l}\text { Campesino en } \\
\text { industrialización }\end{array}$ & $\begin{array}{l}\text { Monocultivos industrializados y patrones de sustento modernos combinados con } \\
\text { policultivos de autoconsumo y recolección silvestre de madera, leña, hierbas y } \\
\text { hongos comestibles, entre otros. }\end{array}$ \\
\hline Monoproductivo \\
\hline $\begin{array}{l}\text { Parcelas de monocultivos a partir de paquetes tecnológicos con insumos } \\
\text { exógenos, semillas híbridas comerciales y uso intensivo de maquinaria } \\
\text { (Revolución Verde) y que dependen asimétricamente de los mercados bursátiles. }\end{array}$ \\
Esta producción ya es una mercancía o commodity.
\end{tabular}

Fuente: Elaboración con base en (Toledo, Alarcón-Chaires y Barón, 2002), (Van der Ploeg, 2010) y (Altieri y Toledo, 2011).

Como ya ha sido analizado por Warman (1978), Toledo et al. (2001), Bartra (2010), Tetreault, Ochoa y Hernández (2013), y muchos otros, el sistema agroalimentario mexicano centrado en la producción de maíz es fundamental por ser un cereal básico. FAO (2012) estimó un consumo promedio per cápita de $49 \mathrm{~kg}$ anuales del cereal para el año 2010 y para este año se verificó un déficit en la disponibilidad de maíz grano de 6.1 millones de toneladas para consumo humano (SAGARPA, 2012). ${ }^{6}$ Siendo enclaves importantes en la producción de maíz blanco para consumo humano en México los estados de Sinaloa, Jalisco, Michoacán, Guanajuato y Tamaulipas, la mayor parte de la producción del grano se canaliza a través de las industrias harineras (Minsa y Maseca), para posteriormente ser comercializada al menudeo en las más de 78 mil tortillerías en México (Massieu y Lechuga, 2002).

Por el lado de la producción, ésta la realizan alrededor de 3.2 millones de agricultores (el 92\% tiene hasta 5 hectáreas) en valles templados mexicanos que suman una extensión total de 6.82 millones de hectáreas (SAGARPA, 2012), en su mayoría son tierras de temporal (alrededor de un 73\%) y primordialmente bajo una lógica agroindustrial, con un rendimiento que va de 1.8 a 3.2 toneladas por hectárea (FAO, 2012). Esto implica una alta mecanización, uso de semillas comerciales, agroquímicos y fertilizantes sintéticos (Massieu y Lechuga, 2002). 
En este escenario rural mexicano, se encuentran en disputa por un lado la tendencia hegemónica de la agricultura industrial de alta productividad y que alimenta a las ciudades a través de la industria harinera y tortillera (Pichardo, 2006) y, por otro la agricultura campesina (Van der Ploeg, 2010) de menor escala que subyace como estrategia de autosuficiencia familiar, aún en los enclaves maiceros agroindustriales.

El discurso del desarrollismo gubernamental en México para argumentar las ventajas del agronegocio y la producción agroindustrial se había venido fincando en los mismos postulados del capitalismo contemporáneo que analizamos anteriormente: por un lado, la eficiencia y rentabilidad de la producción intensiva a gran escala y, por otro lado, en las ventajas competitivas de un grano de maíz mejorado que habría de ser preferido por el mercado (Massieu y Lechuga, 2002). En términos de la construcción de un nuevo actor rural bajo la identidad agroempresarial se diseminó el símbolo del moderno agricultor con tractor y con mochila de aspersión como superior al obsoleto campesino que hace uso de la yunta y la coa (Bartra, 2008). Finalmente, la despolitización de las organizaciones campesinas gremiales del régimen populista priísta y su desarticulación como estructura para acceder al poder se operó mediante la individualización formal de los programas gubernamentales de subsidios, la desaparición del ejido y entidades organizativas, y el fuerte condicionamiento de los pocos subsidios a la previa comprobación de indicadores financieros aceptables sólo bajo el argumento de proyecto productivo (Pichardo, 2006), lo que ha constituido una crisis económica, política y cultural:

“Así pues el desarrollo rural en México ha dado como resultado, la desaparición de culturas profundas, esenciales en la construcción de las identidades nacionales, en nombre de la modernización (...) La apertura unilateral de las importaciones subsidiadas, la caída de los precios agrícolas, la carencia de estrategias de apoyo, los altos costos del crédito, son algunas de las razones de esta crisis. Ahora el campo mexicano sufre la despoblación, a causa de la pobreza, que obliga a miles de mexicanos a emigrar a las grandes ciudades y a Estados Unidos” (Figueroa, Villalvazo y Gerritsen, 2012: 6).

Esta disputa entre la tendencia hegemónica del modelo agroindustrial que busca prevalecer y encajar en la matriz social campesina se ha encontrado con un nexo contradictorio que se muestra como un conjunto sólido de resistencia y que desenmascara la lógica de reproducción del capital.

Como ya anticipábamos arriba, el capitalismo contemporáneo ha sido capaz de recrearse bajo la lógica de fábrica difusa que intensifica la explotación de la fuerza de trabajo, se ha deslocalizado haciendo uso de las redes de comunicación y desdibuja así la dominación de clase, y se ha reinventado como proceso tecnológico desmaterializado y de alta eficiencia. Al mismo tiempo, ha recurrido a la creación de mercancías-símbolo para la construcción de identidades de consumo y como base material de una intersubjetividad global que se identifica con manufacturas y marcas como 
referentes de estatus y poder (Altamira, 2006). Y para articular todo lo anterior, la ideología liberal de los derechos civiles promueve la propiedad privada y la moral individualista bajo un esquema anónimo de democracia light que desactiva la colectivización de las inconformidades reduciéndolas al plano de lo individual.

Pues bien, esta tendencia del capitalismo en la actual fase de la modernidad en México, ha encontrado en el campesinado la mayor resistencia a su dinámica de incorporación civilizatoria (Bartra, 2011); lo que viene a articularse con el fenómeno del cambio climático y, paradójicamente, el rescate de la agricultura campesina como alternativa civilizatoria (Sarukhán, Carabias, Koleff y Urquiza-Haas, 2013). Esto es, no obstante más de 70 años de revolución verde en México, el campesinado continúa produciendo maíz bajo sistemas multifuncionales para el autoconsumo, cuyos excedentes se canalizan en mercados locales. La resistencia del campesinado a la adopción total de la tecnología agroindustrial, que con frecuencia se explicó como ignorancia y anquilosamiento, ahora se rescata, presume y ensalza. Su viabilidad (termoeconómica, agroecológica y sociocultural) se ha reconocido en el Sur (Altieri y Toledo, 2011) y en el Norte (Pretty, 2003) como paradigma de agricultura sostenible (IPCC, 2012).

La tendencia a la exclusión - de familias y territorios enteros de campesinos-, que es propia del capital que se mueve hacia aquellos enclaves en donde se reproduce con mayor facilidad y rapidez, gracias a la existencia de redes comunicacionales y de datos, permitió la marginación, existencia y proliferación de sistemas productivos campesinos diversificados y con alto grado de autosuficiencia que, en un escenario de mercados volátiles, no sólo aporta a la seguridad alimentaria sino a la soberanía alimentaria (Van der Ploeg, 2010).

En definitiva, la producción de maíz en México desnuda la vinculación entre el capitalismo actual y el cambio climático porque, como veremos enseguida, la literatura muestra que ante el fenómeno de la variabilidad de temperatura y lluvias que afecta(rá) al país la única alternativa sostenible y de largo plazo para la producción energéticamente eficiente de alimentos es la agricultura campesina, ya que ha sido uno de los pocos bastiones de resistencia opositora 'al frío interés del capital' que hace de los combustibles fósiles el motor de su progreso (Harvey, 1998).

Más aún, el campesinado y su agricultura diversificada se encuentra endógenamente adaptada a su propio agroecosistema, por lo que en cada rincón de México se encuentra un sistema de agrícola propio (Toledo et al., 2001) que no es susceptible de ser “exportado” y universalizado, como serían las pretensiones del agronegocio. Y esto es de tal suerte, que las implicaciones de la agricultura campesina están íntimamente referidas a un marco cultural plural y múltiple, o mejor dicho, a múltiples marcos culturales referidos al devenir socioecológico endógeno y con ello a particularidades históricas, a preferencias culinarias, a especificidades intersubjetivas, y arreglos ético-prácticos que en su conjunto conforman estructuras 
sociohistóricas y agroecológicas profundamente desalineadas a la reproducción del capital (Bartra, 2008).

Mientras que el capitalismo se desterritorializa, el campesinado está profundamente localizado; mientras que el agronegocio busca una identidad universal como el dinero, la agricultura campesina se identifica con lo concreto de su paisaje; mientras la agricultura industrial calcula sus ganancias individuales, el campesino se vive vinculado a su familia y comunidad rural inmediata. Los estudiosos del fenómeno del cambio climático han señalado a esa agricultura campesina como la alternativa a la agricultura industrial del capitalismo contemporáneo:

“Debido a que el cambio climático restringirá el crecimiento de la agricultura intensa en insumos, las políticas de fomento habrían de apoyarse en la resiliencia de México que deriva de su rica biodiversidad en maíz, así como en el impulso a las prácticas agrícolas sustentables” (Turrent, Wise y Garvey, 2012: 2).

Para cerrar este análisis, exploraremos con mayor profundidad el grado de restricción que plantea el cambio climático a la agricultura industrial y, a la vez, buscaremos precisar si las prácticas agrícolas sustentables pueden estar referidas a alguna variación que se encuentre dentro de la producción industrial agrícola o si en verdad se podrían estar refiriendo a la agricultura campesina, como aquí brevemente la hemos descrito, en franca oposición a la lógica neoburguesa. En el último caso, nos preguntamos ¿por qué no declararlo abiertamente? Quizás exista de por medio un planteamiento político incómodo. Veamos.

\section{El cambio climático: ¿ fin de la agricultura industrializada del maíz en México?}

Existe una creciente diversidad de análisis referidos al fenómeno del cambio climático y reflexiones disímbolas que escapan a los alcances de esta reflexión ofrecer una clasificación del tema. En términos generales, para el (IPCC, 2007) las estrategias ante los efectos de sequías, lluvias intensas, granizo, heladas, huracanes, etcétera, tendrían que transitar por la vía de la adaptación y mitigación. Esto es, diseñar planes para adaptarse a los cambios climatológicos y para reducir sus posibles impactos y probables efectos en todos los ámbitos sociales y económicos. En este sentido, el documento del IPCC realiza un reconocimiento explícito, aunque breve, de que las acciones de adaptación no son suficientes si no existen acciones que reduzcan la emisión de gases de efecto invernadero (IPCC, 2012).

Dentro de las estrategias de adaptación y mitigación se han considerado políticas públicas encaminadas a la racionalización en el uso de combustibles fósiles, la reforestación y otras muchas más cuya eficacia, complejidad e implicaciones presentan una dramática variabilidad por la combi- 
nación de factores logísticos, institucionales y políticos, entre muchos otros, como el presupuestal, ${ }^{8}$ a pesar de que a nivel mundial existe una enorme asimetría en la cantidad de emisiones de gases de efecto invernadero y, por tanto, en la responsabilidad directa del cambio climático (World Resources Institute, 2009). ${ }^{9}$

En las publicaciones podemos encontrar una amplia gama de estudios relacionados con el cambio climático y sus posibles impactos en la producción agropecuaria en México. ${ }^{10}$ Destaca sin duda, por su solidez y amplitud, la compilación de datos e información que presenta el Panel Internacional para el Cambio Climático (2012) en el reporte llamado "Managing the risks of extreme events and disasters to advance climate change adaptation", en el que se afirma que habiendo analizado diversos casos, la economía moral ${ }^{11}$ ha demostrado constituir una fuerte estrategia de resiliencia social de frente al cambio climático:

"Muchos estudios muestran que las relaciones sociales basadas en la economía moral siguen presentes, como en las instituciones tradicionales que regulan el acceso y uso de las tierras de propiedad comunitaria (Sundar y Jeffery, 1999; Rist, 2000; Hughes, 2001; Trawick, 2001; Rist et al, 2003). La economía moral impacta las formas de cooperación y organización intrafamiliar y representan una fuente importante y todavía existente de fomentar la acción colectiva que sirve como una condición favorable para prevenir y hacer frente a los riesgos relacionados con la gestión de recursos” (IPCC, 2012: 309).

Sin embargo, la economía moral no es una praxis que se verifique de manera aislada en el espacio rural, sino que corresponde a marcos civilizatorios que han sido ampliamente documentados y analizados por economistas (Campos y Naredo, 1980), agroecólogos (Altieri y Nicholls, 2000), biólogos (Dobbs y Pretty, 2004), antropólogos (Haenn y Wilk, 2006), filósofos (Shiva, 2006), sociólogos (Sevilla y Cuéllar, 2009), agrónomos (Van der Ploeg, 2010), historiadores (Tortolero, 1996), entre otros, e implica una serie de prácticas socioecológicas que coloca la estrategia de mitigación, entonces, en una dimensión integral y compleja: ${ }^{12}$

“Los sistemas agrícolas sostenibles pueden mejorar la salud del suelo, incrementar la eficiencia del agua, y hacer el mejor uso de la diversidad biológica para el control de plagas y enfermedades. Cuando se pone todo ello junto, existen importantes interacciones sinérgicas, mejorando el rendimiento del sistema en su conjunto" (Pretty, 2003: 20).

Más profundamente, la agricultura sustentable -o sea, la estrategia de mitigación en el sistema agroalimentario- implica no sólo una reducción en el uso de combustibles fósiles, sino una ruptura en la tendencia industrializadora de la agricultura dominante a base de insumos químicos y fertilizantes sintéticos, y un reconocimiento de que la agricultura sustenta- 
ble es aquella de carácter campesino con fortísima raíz étnica que ha sido capaz de apropiarse de los ecosistemas y adaptarse a ellos:

“(...) a una escala planetaria, la diversidad cultural de la especie humana se encuentra estrechamente asociada con las principales concentraciones de biodiversidad existentes (...) La evidencia científica muestra, además, que prácticamente no existen fragmentos importantes del planeta que no hayan sido habitados, modificados o manipulados a lo largo de la historia. Aunque parezcan vírgenes, muchas de las últimas regiones silvestres más remotas o aisladas están habitadas por grupos humanos o lo han estado por milenios” (Toledo et al., 2001: 8).

En última instancia, nos parece que los planteamientos sistemáticos relacionados con el cambio climático y que circulan por la literatura científica se podrían dividir en dos muy básicos: los que sugieren realizar ajustes y cambios dentro del capitalismo contemporáneo y aquellos que sugieren, ante la variabilidad climática, un viraje civilizatorio fuera de la lógica de la reproducción del capital.

Es en este sentido que creemos que la Naturaleza ha herido de muerte a la agricultura industrial, en particular, y a la neoburguesía transnacional, en lo general, al plantear la insostenibilidad de perpetuar la lógica extractiva capitalista y su producción industrializada de mercancías. La argumentación sobre reformular la agricultura industrial para trocarse "sustentable", por ejemplo, desde la economía ambiental o la economía verde, en realidad son planteamientos políticos revestidos de argumentos científicos porque hacen parecer que es posible incorporar "prácticas sustentables” en la búsqueda de lucro, cuando es de suyo el cálculo utilitario y la minimización de costos con la finalidad de apropiación de productos socialmente creados (Marx, 2001) y de bienes comunes (Martínez-Alier, 2011).

Esto es, la narrativa sobre un sistema agroalimentario sustentable, que no transparenta su postura con relación a la reproducción del capital, se engaña a sí mismo porque invisibiliza (¿o ignora?) la contradicción primigenia en que se funda el sistema capitalista como modelo civilizatorio, a saber, la privatización o apropiación individual de la riqueza socialmente creada mediante el trabajo (como acción transformadora del colectivo humano hacia la naturaleza) y que circula a través de los intercambios, o sea, en el mercado (Marx, 2001).

Entonces, cuando la cosecha de maíz es ofertada por el agricultor en el mercado capitalista, ésta es (de)valuada como una mercancía con valor de cambio y, al ocultar su valor de uso como alimento básico, se intercambia por dinero. En el momento de comercializarse bajo forma de tortillas en México, la cantidad de dinero necesaria para adquirir el maíz como mercancía se ha cuadruplicado porque el consumidor final le devuelve su valor de uso como alimento y el sobreprecio le parece aceptable ante la posibilidad de padecer hambre. 
En ese proceso fue el capital (Marx, 2001), de los accionistas de la agroindustria e intermediarios, lo que creció mediante la apropiación del valor de los servicios ecosistémicos (lluvia, nutrientes del suelo, sol, aire, clima), del valor de trabajo del agricultor, y del salario del consumidor (que a su vez es la expresión monetaria del valor de su fuerza de trabajo) contenido en el maíz y su proceso de intercambio.

Como podemos ver con claridad, un sistema agroalimentario como el del maíz en México es un proceso social (agricultores y consumidores) de intercambios mediados por la agroindustria, en donde se verifica una apropiación socializada de servicios ecológicos a través del trabajo agrícola para satisfacer, una necesidad social fundamental como la alimentación. El capitalismo, entonces, es el proceso sistemático de apropiación privada o privatización del valor (de bienes, beneficios, servicios, satisfactores, productos, etcétera) creado socialmente y que se expresa en el capital: bajo forma de propiedad privada de medios de producción, de cuentas privadas de dinero y de patentes de conocimiento especializado (Altamira, 2006).

Por lo anterior, es radicalmente imposible hablar de sustentabilidad dentro de la lógica del capital porque existe una incompatibilidad primigenia entre el proceso capitalista de privatización (individual) de la riqueza social y la consideración de la biodiversidad, saberes locales y economía moral como bienes comunes y colectivos, es decir, no-privados ni susceptibles de ser privativos o exclusivos de ciertos individuos (Marx, 2001).

En ese sentido, al referirnos a que el cambio climático requiere una agricultura sustentable que mitigue la emisión de gases de efecto invernadero -por la vía de constituirse como sumidero de carbono y eliminar su dependencia de petroinsumos- estamos indicando que es imprescindible asumir que el subsistema agroalimentario maicero (y todos los demás que conforman el sistema alimentario) es un bien común que implica trabajo, intercambios y agroecosistemas (o territorios) que conforman un sistema socialmente creado, que no creado por alguna empresa ni por algún individuo, ${ }^{13}$ y por lo tanto ello implica el abandono del sistema capitalista contemporáneo como modelo civilizatorio que funciona sobre la base de la propiedad privada de valores construidos a través del colectivo humano (Marx, 2001).

Ahora podremos comprender porqué en el debate sobre las estrategias agropecuarias ante el cambio climático se presenta oculta una disputa política, que siempre es por la dominación y el poder: cuando se propone como solución la creación de organismos genéticamente modificados, o la sustitución de insumos químicos por otros orgánicos de manufactura, cuando se identifican esquemas de comercialización "verde", o se sugiere la conformación de esquemas asociativos más “competitivos”, o se analizan las probabilidades de que la variabilidad climática no sea tan severa, en realidad lo que se está proponiendo es continuar con la reproducción del capital, tal y como lo hemos señalado anteriormente y revestirse de jaculatorias sobre una sustentabilidad. 
Cuando organizaciones y movilizaciones sociales como La Vía Campesina, ${ }^{14}$ la Campaña Nacional Sin Maíz no hay País, ${ }^{15}$ la Asociación Nacional de Afectados Ambientales, ${ }^{16}$ entre otras, plantean la revaloración de la (agri)Cultura campesina, que es multifuncional y biodiversificada, lo que se está proponiendo es una ruptura con el sistema de privatización (o apropiación) individual de bienes (tangibles e intangibles) socialmente creados porque tienen valor de uso para el colectivo humano por encima de cualquier valor de cambio. Dicho de otra forma, la agricultura campesina responde a un paradigma civilizatorio alternativo al de la reproducción del capital y no ha podido ser absorbido por el capitalismo contemporáneo porque en México, como en otras regiones del planeta, encontramos múltiples y muy diversos marcos culturales que atienden a una pluralidad de condiciones históricas, ecológicas y socioeconómicas (Toledo et al., 2001) que, en su mayoría, tienen en común una dinámica de reproducción social que se funda en bienes sociales para usufructo colectivo, y eso es opuesto a la lógica de apropiación individual de tangibles e intangibles colectivos y la externalización de costes como lo hace el capitalismo agroempresarial (Van der Ploeg, 2010).

En nuestra interpretación sobre las implicaciones del cambio climático para el sistema agroindustrial en la producción de maíz en México, es fundamental resituar la agricultura campesina que ha probado ser más resiliente ante la variabilidad climatológica, mucho más autosuficiente, sostenible ecológicamente y viable económicamente, de acuerdo con Pretty (2003).

Pero ello tiene implicaciones civilizatorias muy severas y debatibles, que se localizan fuera de los alcances de esta reflexión inicial pero que brevemente enunciaremos, por un lado requerimos orientar Estados-nación a la reproducción social y dejar atrás la reproducción del capital y, por otro, necesitamos encontrar planteamientos civilizatorios propios, diversos y diferenciados acorde a las circunstancias sociopolíticas, histórico-culturales, etcétera., que quizás tengan en común una tendencia hacia el decrecimiento.

Los intelectuales europeos del decrecimiento y economistas ecológicos como Martínez-Alier (2008) han señalado a partir de los estudios termo-económicos realizados por Nicholas Georgescu-Roegen (1993), que es imposible el crecimiento ilimitado del capital en tanto no existen materiales físicos ni energéticos para que ello suceda y que, al haber ya rebasado la capacidad de carga planetaria, tenemos que empezar a "desconectar" sistemas industriales del alto consumo material y energético, para transitar a una genuina desmaterialización y reducción de la entrópica reproducción del capital basada en combustibles fósiles y en el extractivismo, sin que ello implicare menor calidad de vida y bienestar, pues habría que desechar la producción de satisfactores accesorios y de carácter suntuario.

Ante la crisis ecológica y el cambio climático, esta corriente de pensamiento bioeconómico posiciona valores como la conservación de los biomas y una sociedad frugal, como única alternativa al colapso civilizatorio 
de la especie humana. Estas ideas resultan absurdas y escandalosas para los intelectuales de la economía neoclásica y para la clase beneficiaria del capitalismo contemporáneo, y desde esa perspectiva tienen toda la razón.

En un país como México en donde el sistema agroalimentario se encuentra dominado por la racionalidad de la privatización de la naturaleza (intensificándose el llamado neoextractivismo), ${ }^{17}$ del trabajo (con crecientes reformas estructurales en materia de flexibilidad del empleo), ${ }^{18}$ de las redes de intercambio (profundizando en reformas fiscales y financieras neoliberales $)^{19}$ y de la identidad cultural como imagen de marca, es inconcebible la idea de ralentizar la economía del capital. En un proyecto de país alternativo, en ruptura con el capitalismo contemporáneo, no solo es posible sino que ya existe:

“Para la primera década del siglo XXI, se tenían contabilizados 1.5 mil millones de pequeños propietarios, agricultores familiares y de población indígena, manejando aproximadamente 350 millones de pequeñas fincas. Es difícil establecer las cifras reales, pero algunos estiman que el 50\% de estos campesinos producen bajo un sistema de manejo y conservación agrícola -que son fiel testimonio de la notable capacidad de recuperación de los agroecosistemas tradicionales frente a la cambiante dinámica de los medios ambiente y económico- al tiempo que contribuye sustancialmente a la seguridad alimentaria a escala local, regional y nacional” (Altieri y Toledo, 2011: 8).

En palabras de los actuales funcionarios del Instituto Nacional de Ecología y Cambio Climático, institución gubernamental en México, ${ }^{20}$ la estrategia de mitigación en materia de agricultura sustentable de frente al cambio climático requeriría:

“Impulsar la adopción de sistemas productivos agropecuarios más adecuados con las condiciones ambientales de cada región del país, multifuncionales y diversificados con una visión de manejo integral de los ecosistemas. En el ámbito terrestre, entre las opciones de reconversión productiva están la adopción de la agricultura orgánica y la transformación de la agricultura y la ganadería convencionales en sistemas agroecológicos y agroforestales” (Sarukhán, Carabias, Koleff y Urquiza-Haas, 2013: 19).

Como señala Tortolero (1996), desde la aparición de las haciendas coloniales y hasta la fecha, pasando por el Porfiriato, los gobiernos y empresarios en México siempre han tendido a forzar la implantación de sistemas agroalimentarios intensivos para alimentar las ciudades y a menospreciar la tecnología de la agricultura campesina multifuncional, la de la coa y las chinampas, ${ }^{21}$ por lo que el cambio climático nos sitúa ante un parteaguas civilizatorio como país en donde para producir alimentos de manera sostenible tendremos que recurrir al fomento de la agricultura campesina que se encuentra ampliamente diversificada conforme los diversos ecosistemas e historia social en la geografía del país (Toledo, Alarcón-Chaires y Barón, 
2002) y cuya orientación principal es la reproducción social (y no del capital) por debajo de la capacidad de carga ecológica, haciendo uso de innovaciones tecnológicas propias, aprovechando los materiales y recursos endógenos y, en definitiva, repensando nuestra mexicanidad. ${ }^{22}$

\section{Conclusiones}

El cambio climático tiene sin duda relación directa con la actividad industrial basada en la quema de combustibles fósiles que constituye el pilar en el que se cimbra el crecimiento económico del sistema capitalista y la agricultura industrial en México (Altieri y Toledo, 2011).

La agricultura sustentable, para la producción de maíz y otros alimentos, que proponen las agencias multilaterales (FAO, 2012) y académicos universitarios (Pretty, 2003), necesariamente pasa por una ruptura con el capitalismo agroindustrial porque la externalización de costos ecológicos y la apropiación individual del trabajo social condujo al uso indiscriminado del petróleo que ha trastornado el ciclo del carbono del planeta (World Resources Institute, 2009).

Las alternativas que se plantean sobre el cambio climático conllevan un alto contenido político, a pesar de que se presentan como análisis neutrales emanados de una lógica cartesiana. En efecto, aquellos planteamientos que consideran que es posible la sustentabilidad agroalimentaria dentro de los ámbitos de la reproducción del capital, implícitamente aceptan (o explícitamente ignoran) que el capitalismo industrial continúe apropiándose de los bienes comunes (naturaleza, atmósfera, agua, etcétera) y de la riqueza social (trabajo, medios de producción y conocimiento) con fines de dominación (Altamira, 2006).

La agricultura campesina como la describen Altieri y Toledo (2011) y Van der Ploeg (2010) es la alternativa posible para "enfriar" el planeta de manera sostenida y a la vez alimentar a la especie humana, requiere de otra epistemología y teleología. Sin embargo, esto tiene implicaciones civilizatorias y requiere una discusión colectiva de amplia envergadura en términos de proyecto de nación. Un primer paso son la serie de planteamientos se que han realizado en diversos espacios sobre los conflictos ecológicos distributivos (Martínez-Alier, 2011) y cada vez hay más claridad y consenso de lo que no se quiere. Aún falta enunciar lo que sí se quiere. Hay que darnos prisa. 


\section{Notas}

${ }^{1}$ Un interesante análisis es presentado por Chen y Ravallion donde es posible observar que para 2005 alrededor del 57.6\% de la población mundial sobrevivió con menos de \$2.50 dólares americanos diarios. Estas y otras cifras y referencias al respecto se encuentran en http://www.globalissues.org/article/26/poverty-facts-and-stats

${ }^{2}$ Nosotros nos ubicaremos escépticos ante lo generalizador de ese planteamiento porque si bien reconocemos la tendencia hegemónica del neoliberalismo a escala mundial, es de suyo conformar amplias dinámicas contradictorias de exclusión social y por tanto, en un planeta de siete mil millones de habitantes, donde alrededor de la mitad de ellos están subsistiendo en la periferia bajo las más diversas formas y arreglos socioculturales endógenos que constituyen la resistencia más férrea al capitalismo neoliberal y su lógica totalizante (Bartra, 2008), cuando menos habría que discutir, en otro momento y lugar, bajo qué condiciones el neoliberalismo podría ser, en efecto, global.

${ }^{3}$ Su contraparte es cómo las redes comunicacionales y, particularmente, la internet ha permitido la circulación y la construcción de estrategias de resistencia que se apropian los contenidos hegemónicos y los subvierten con éxito que es debatible, véase la reflexión de Escobar (2010). Para Kari-Hans Kommonen y el ARKI Research Group del Laboratorio de Medios de la Universidad de Helsinski de Arte y Diseño, el internet es un primer paso en el desarrollo de un más complejo mediaespacio. Este mediaespacio es central para elaborar y negociar ideas, estructuras y prácticas. Véase: http://arki.uiah.fi

${ }^{4}$ Véase el trabajo de Joan Martínez-Alier, Oscar Carpintero, José Manuel Naredo, Herman Daly, Antonio Valero, entre otros.

${ }^{5}$ Véase el trabajo de Jorge Riechmann, Víctor M. Toledo, Alain Lipietz, Iván Illich, André Gorz, entre otros.

6 Sobre la base de 110 millones de habitantes por un consumo anual medio de 49 kgs/ habitante. Para 2025, la demanda será de 39 millones de toneladas anuales, según el reporte de (Turrent, Wise y Garvey, 2012).

${ }^{7}$ El Servicio de Información Agroalimentaria y Pesquera estimó para 2008 el número de tortillerías en 78,852. Véase en http://www.siap.gob.mx/opt/123/21/20.html .

${ }^{8}$ El Centro Mario Molina presenta un breve análisis del presupuesto gubernamental para el ejercicio fiscal 2013 destinado a acciones en materia de Cambio Climático que suman alrededor de 28 mil millones de pesos a través de 11 dependencias gubernamentales mexicanas, breve documento que se puede consultar en http:// centromariomolina.org/cambio-climatico/analisis-del-presupuesto-de-la-federacion-enmateria-de-cambio-climatico/

${ }^{9}$ Véase en el sitio del World Resources Institute diversos gráficos, particularmente el que compara a los 12 países con mayores emisiones per cápita de CO2 en http:// www.wri.org/resources/charts-graphs/top-12-co2-emitting-countries-their-capitaemissions-2004 y el origen de los gases de efecto invernadero por tipo de actividad antropogénica en un diagrama de Sankey en http://www.wri.org/resources/charts-graphs/ world-greenhouse-gas-emissions-2005 
${ }^{10}$ Véase los estudios de S. R. Saldaña-Zorrilla (2007), "Socioeconomic vulnerability to natural disasters in Mexico: rural poor, trade and public response”; de A.L. Luers, D.B. Lobell, L.S. Sklar, C.L. Addams, y P.A. Matson (2003), "A method for quantifying vulnerability, applied to the Yaqui Valley, Mexico”; de H. Eakin (2005), "Institutional change, climate risk, and rural vulnerability: Cases from Central Mexico”; de F. AragonDurand (2007), "Urbanisation and flood vulnerability in the peri-urban interface of Mexico City”; de E. A. Rodriguez-Oreggia, de la Fuente, R. de la Torre, H. Moreno, y C. Rodriguez, (2010), "The Impact of Natural Disasters on Human Development and Poverty at the Municipal Level in Mexico"; de L. Villers y I. Trejo (2004), "Evaluación de la vulnerabilidad en los sistemas forestales. Cambio Climático”; de R. Boyd y M.E. Ibarrarán (2009), "Extreme climate events and adaptation: An exploratory analysis of drought in Mexico"; de E. Hammar-Klose y R. Thieler (2001), "Coastal Vulnerability to Sea-Level Rise: A Preliminary Database for the US Atlantic, Pacific and Gulf Of Mexico Coasts”; de V. Cardenas, S. Hochrainer, R. Mechler, G. Pflug, y J. Linnerooth-Bayer, (2007), "Sovereign financial disaster risk management: the case of Mexico"; de S. Feng, A.B. Krueger, y M. Oppenheimer (2010), "Linkages among climate change, crop yields and Mexico-US cross-border migration”; entre otros que están enfocados en la República Mexicana.

${ }^{11}$ Véase el trabajo de Edward P. Thompson (2000), Costumbres en común, Barcelona: Crítica.

${ }^{12}$ Nótese que en la experiencia 'de campesino a campesino', y en general en la agricultura campesina, las mujeres y sus hijos tienen una participación fundamental en el cuidado y selección de las semillas. Véase el sitio http://www.pidaassa.org/ Y de manera más general para tener una perspectiva más amplia sobre género y ruralidad véase libro de Jeanine Anderson et al. (2011), Mujer rural, cambios y persistencias en América Latina. Disponible en http://americalatina.landcoalition.org/sites/default/files/ libro\%20Mujer\%20Rural.pdf

${ }^{13}$ Esto es fundamental porque consideramos que las formas históricas en que se han configurado las sociedades humanas no son "evoluciones de la naturaleza social”, sino construcciones colectivas que van adoptando giros sistémicos y estructurales originados en múltiples factores para nada atribuibles a una suerte de predeterminación ni destino metafísico.

${ }^{14}$ Véase http://www.viacampesina.org/es/

${ }^{15}$ Véase http://www.sinmaiznohaypais.org/

${ }^{16}$ Véase http://www.afectadosambientales.org/

${ }^{17}$ Véase http://www.biodiversidadla.org

${ }^{18}$ Véase http://www.jornada.unam.mx/2013/08/08/edito

${ }^{19}$ Véase http://www.jornada.unam.mx/2011/05/08/sociedad/037a1soc

${ }^{20}$ Véase en www.inecc.gob.mx 
Polis, Revista Latinoamericana, Volumen 14, $N^{\circ}$ 40, 2015

${ }^{21}$ La coa es un instrumento de labranza y la chinampa es un sistema agroecológico diversificado en policultivos muy difundido en el centro de México y que aún existe en la zona del Lago de Xochimilco (Patrimonio Cultural de la Humanidad, según UNESCO). Véase http://www.jornada.unam.mx/2013/06/15/cam-chinampas.html

${ }^{22}$ Es muy interesante la reflexión que hace Escobar respecto de la necesidad de descolonización de nuestro pensamiento Latinoamericano y permitir, como dice él, imaginar el 'postdesarrollo' (Escobar, 2010). Una veta interesante de análisis para México, en términos de imaginar un proyecto de nación alternativo, podría ser el postdesarrollo en relación con el decrecimiento (Martinez-Alier, 2008) como enfoques críticos. 


\section{Bibliografía}

Altamira, C. (2006), Los marxismos del nuevo siglo. Biblos. Buenos Aires.

Altieri, M. A. y Nicholls, C. I. (2000), Agroecología. Teoría y práctica para una agricultura sustentable. PNUMA. México.

Altieri, M. A. y Toledo, V. M. (2011), “La revolución agroecológica en Latinoamérica”. The Journal of Peasant Studies, 38 (3), 587-612.

Bartra, A. (2008), “Fin de fiesta. El fantasma del hambre recorre al mundo”. Argumentos, 21 (57), 15-31.

Ídem. (2010), “Tiempos turbulentos”. Argumentos, 23 (63), 91-119.

Ídem. (2011), Tiempos de mito y carnaval. Itaca. México DF.

Bech, U., Giddens, A. y Lash, S. (1994), Modernización reflexiva. Alianza Editorial. Madrid.

Campos, P. y Naredo, J. M. (1980), La energía en los sistemas agrarios. Recuperado el 27 de Mayo de 2013, de Ministerio de Agricultura, Alimentación y Medio Ambiente de España: www.magrama.gob.es

Delgado, M. (2010), “El sistema agroalimentario globalizado: imperios alimentarios y degradación social y ecológica”. Economía Crítica (10), 3261.

Dobbs, T. L. y Pretty, J. N. (2004), “Agrienvironmental stewardship schemes and multifunctionallity”. Agricultural Economics, 26 (2), 220237.

Escobar, A. (2010), Una minga para el postdesarrollo: lugar, medio ambiente y movimiento sociales en las transformaciones globales. Universidad Nacional Mayor de San Marcos. Lima.

Fair, H. (2008), “El sistema global neoliberal”. Polis, 21, 1-24.

FAO. (2012), Food and Agriculture Organization. Recuperado el 9 de Junio de 2013, de FAO Statististical Yearbook 2012: www.fao.org

Figueroa, P., Villalvazo, V. y Gerritsen, P. (3-4 de Mayo de 2012), Resistencia y autonomía campesina en tiempos de globalización neoliberal: casos del Sur de Jalisco. Primer pre-congreso ALASRU. Globalización y agricultura. Nuevas perspectivas en la sociología rural, págs. 1-25.

Georgescu-Roegen, N. (1993), The entropy law and the economic problem. MIT Press. Londres. 
Giddens, A. (2000), Un mundo desbocado: los efectos de la globalización en nuestras vidas. Taurus. Madrid.

Haenn, N. y Wilk, R. R. (2006), The environment in anthopology: a reader in ecology, culture and sustainable living. New York University Press. Nueva York y Londres.

Harvey, D. (1998), La condición posmoderna. Amorrortu. Buenos Aires.

Hellin, J., Groenevald, S. y Keleman, A. (2012), “Impact pathways of trade liberalization on rural livelihoods: a case study of smallholders maize farmers in Mexico”. Iberoamericana de Estudios de Desarrollo, 1 (1), 59-83.

IPCC. (2007), Climate Change 2007: Shythesis Report. IPCC. Valencia.

Ídem. Working Group II. (2007), Climate change 2007: Impacts, adaptation and vulnerability, contibution to the Fouth assessment of IPCC. Cambridge University Press. Cambridge.

Ídem. (2012), Managing the risks of extreme events and disasters to advance climate change adaptation. IPCC. Cambridge University Press. Cambridge \& New York.

Lash, S. (1997), Sociología del posmodernismo. Amorrortu. Buenos Aires.

Luhmann, N. (1997), Observaciones de la modernidad. Racionalidad y contingencia en la sociedad moderna. Paidós. Barcelona.

Lyotard, J. F. (1989), La condición postmoderna: informe sobre el saber. Cátedra. Madrid.

Martínez-Alier, J. (2011), El ecologismo de los pobres. Conflictos ambientales y lenguajes de valoración. Icaria. Barcelona.

Ídem. (2008), “Decrecimiento sostenible: París, abril del 2008”. Ecología Política, 51-58.

Marx, K. (2001), El Capital. Crítica de la economía política. Fondo de Cultura Económica. México DF.

Massieu, Y. y Lechuga, J. (2002), “El maíz en México: biodiversidad y cambios en el consumo”. Análisis Económico, 17 (36), 281-303.

Nadal, A. y Wise, T. (2009), “Los costos ambientales de la liberalización agrícola: el comercio de maíz entre México y EEUU en el marco del NAFTA”. Globalización y Medio Ambiente, 49-92.

Organización de las Naciones Unidas para la Alimentación y la Agricultura. (2003), Perfiles nutricionales por países FAO. Recuperado el 27 de Mayo 
de 2013, de Food and Agriculture Organization for the United Nations: www.fao.org

Pichardo, B. (2006), La revolución verde en México. Agraria (4), 40-68.

Pretty, J. (2003), “Agroecology in developing countries: the promise of a sustainable harvest”. Environment, 45 (9), 10-20.

SAGARPA. (2012), Secretaría de Agricultura, Ganaderia, Desarrollo Rural, Pesca y Alimentación. Recuperado el 27 de Mayo de 2013, de SAGARPA: www.sagarpa.gob.mx

Sarukhán, J., Carabias, J., Koleff, P. y Urquiza-Haas, T. (2013), Capital natural de México: acciones estratégicas para su valoración, preservación y recuperación. CONABIO. México, DF.

Sevilla G., E. y Cuéllar P., M. (2009), “Aportando a la construcción de la soberanía alimentaria desde la agroecología”. Ecología Política (38), 43-52.

Shiva, V. (2006), Manifiesto para una democracia de la tierra. Justicia, Sostenibilidad y Paz. Paidós. Barcelona.

Tetreault, D., Ochoa, H. y Hernández González, E. (2013), Conflictos socioambientales y alternativas de la sociedad civil. ITESO. Guadalajara.

The Royal Society (2012), People and the Planet. The Royal Society. Londres.

Toledo, V. M., Alarcón-Chaires, P. y Barón, L. (2002), La modernización rural de México: un análisis socioecológico. SEMARNAT. México DF, México.

Toledo, V., Alarcón-Chaires, P., Moguel, P., Olivo, M., Cabrera, A. y Leyequien, E. (2001), “El Atlas etnoecológico de México y Centroamérica: fundamentos, métodos y resultados”. Etnoecológica, 6 (8), 7-41.

Tortolero, A. (1996), “Historia agraria y medio ambiente en México: estado de la cuestión”. Historia Agraria (11), 151-178.

Turrent, A., Wise, T. y Garvey, E. (2012), Factibilidad de alcanzar el potencial productivo de maíz en México. WWICS. Massachusetts.

Van der Ploeg, J. D. (2010), Nuevos campesinos. Campesinos e imperios alimentarios. Icaria. Barcelona.

Warman, A. (1978), "Desarrollo capitalista o campesino en el campo mexicano”. Revista Comercio Exterior, 29 (4), 399-403.

World Resources Institute (17 de Febrero de 2009), Aggregate contributions 
Polis, Revista Latinoamericana, Volumen 14, $N^{\circ}$ 40, 2015

of major GHG emitting countries: 2005. Recuperado el 9 de Junio de 2013, de www.wri.org/resources/charts-graphs/aggregate-contributions-major-ghgemitting-countries-2005

Recibido: 18.10.2013

Aceptado: 30.05.2014 